\title{
Effect of engaged learning upon lecture learning method on Outcome Based Education in Nursing - An experimental study
}

\author{
Ms. Vaidyanathan Radha ${ }^{1}$, Dr. Pratibha A Chandekar ${ }^{2}$ \\ ${ }^{1}$ (Professor, Child Health Nursing, Maharashtra University of Health Sciences, Nashik \& \\ Paediatric Matron, Command Hospital, Pune, Maharashtra, India) \\ ${ }^{2}$ (Dean, Allied Health Sciences \& Principal, CON, Pravara Institute of Medical Sciences, Loni, Ahmednagar, \\ Maharashtra, India)
}

\begin{abstract}
Teaching learning is fruitful and permanent if the total situation is related to the life situation and in the life situation, especially for health science students. Nowadays, participatory approach (Engaged Learning - EL) is widely recognized and practiced over the Lecture Learning (LL) method in which the student is motivated and equipped to enjoy an active role. A Randomized block experimental design was undertaken with a structured validated common test for standard reference assessment of all samples, for assessing the effectiveness of Engaged Learning over Lecture Learning method. $37.9 \%$ of the group with Lecture Learning had gained knowledge from average to good and excellent level \& $88 \%$ of the group with Engaged Learning had similar level of knowledge gain. Engaged learning is intended to be a conceptual framework for technology based education that can result expected outcome by nursing students in recognition of the changing needs of the 21 st century.
\end{abstract}

Keywords: Engaged learning, Education, Lecture Learning, Outcome Based Education, Teaching

\section{Introduction}

Teaching learning process is influenced by the totality of the situation, especially for health science students. Teaching learning is fruitful and permanent if the total situation is related to the life situation and in the life situations. In nursing education too, effective harmonization of teaching and learning activities are essential to ascertain the fulfillment of the desired outcomes (Outcome Based Education - OBE). Nowadays, participatory approach (Engaged Learning - EL) is widely recognized and practiced over the Lecture Learning (LL) in which the student nurse is motivated and equipped to enjoy an active role in the teaching- learning process, which otherwise is perceived as stressful.

\subsection{Lecture Learning}

\section{Operational Meaning}

Lecture is a method of education in which a teacher gives an oral presentation intended to present information or teaches people about a particular subject. This method has a passive student, unidirectional with no unique value to individuality of students, in which the cognitive process is inactive and critical thinking is nil.

\subsection{Engaged Learning}

By this all student activities involve dynamic cognitive processes such as creating, problem-solving, reasoning, decision-making, and evaluation. In this approach, the student is motivated and equipped to enjoy an active role in the teaching- learning process, due to the meaningful nature of the learning environment and activities. This has its roots from the constructivism theory.

\subsubsection{Constructivism theory}

Constructivism is a psychological theory of knowledge (epistemology) which argues that humans generate knowledge and meaning from their experiences - developed by Seymour Papert.

Constructivist theory: Formalization of the theory of constructivism is generally attributed to Jean Piaget, who articulated mechanisms by which knowledge is internalized by learners. Piaget's theory of Constructivist learning has had wide ranging impact on learning theories and teaching methods in education and is an underlying theme of many education reform movements suggest that learning is accomplished best using a hands-on approach engagement theory places a great deal of emphasis on providing an authentic (i.e., meaningful) setting for learning, something not present in previous models environment and activities.

These three components, summarized by Relate-Create-Donate, imply that learning activities:

* occur in a group context (i.e., collaborative teams) 
* are project-based

* have an outside (authentic) focus

It is suggested that these three methods result in learning that is creative, meaningful, and authentic. So engagement theory is intended to be a conceptual framework for technology-based learning and teaching

\subsection{Outcome Based Education}

OBE focus on the students' learning outcomes (i.e. how much and how well the students have learnt), this could imply that students with different abilities will follow different paths to reach their goals and may finish at different times.

OBE promises high level of learning for ALL students as it facilitates the achievement of the outcomes, characterized by its appropriateness to each learner's development level and active and experienced-based learning. Moreover, knowing that this system is going to be used would also give students the freedom to study the content of the course in a way that helps them learn it.

\section{1 objectives :-}

\section{Materials \& Methodology}

- Study the effect of EL and LL method on OBE in nursing

- Compare the difference of learning effectiveness by EL \& lecture methods on OBE in nursing

\subsection{Design :-}

Randomized Block Experimental Study design was adopted to conduct the study as per the established research protocol.

\subsection{Setting :}

One of the premier nursing colleges conducting UG, PG and post basic diploma courses in Pune was selected for conducting the study.

\subsection{Population}

The population of this study constituted the senior baccalaureate nursing students from Colleges of Nursing in Pune, India.

\subsection{Sampling}

Simple Random Sampling by computer generated randomization was done and students were finally enrolled in the study after pretest. Among those who attended the lecture learning sessions alone (on all critical care nursing procedures), 68 samples were assigned to control group and among those who completed all the planned tasks, 130 were enrolled into the experimental group, as per the established inclusion criteria.

\subsection{Tools}

Control group attended the lecture learning sessions alone and reported back for a post-test. Experimental group were exposed to Engaged Learning in which they were formed into small groups of $10-12$ in number and were subjected to various small projects, presentations, skill training, video assisted learning, simulations, computer assisted learning and quiz, before taking the post-test. Data was gathered from a structured validated 20 items common test Questionnaire that was used for standard referenced assessment of all samples.

\subsection{Statistical Techniques}

Researchers used the Simple Percentage method for analyze \& interpretation of the collected data. Collected data was tabulated and analyzed using descriptive statistics. Inferential statistics like paired ' $t$ ' test was used for assessing the effectiveness of Engaged Learning over Lecture Learning method, SPSS 17 version.

\subsection{Research protocol}




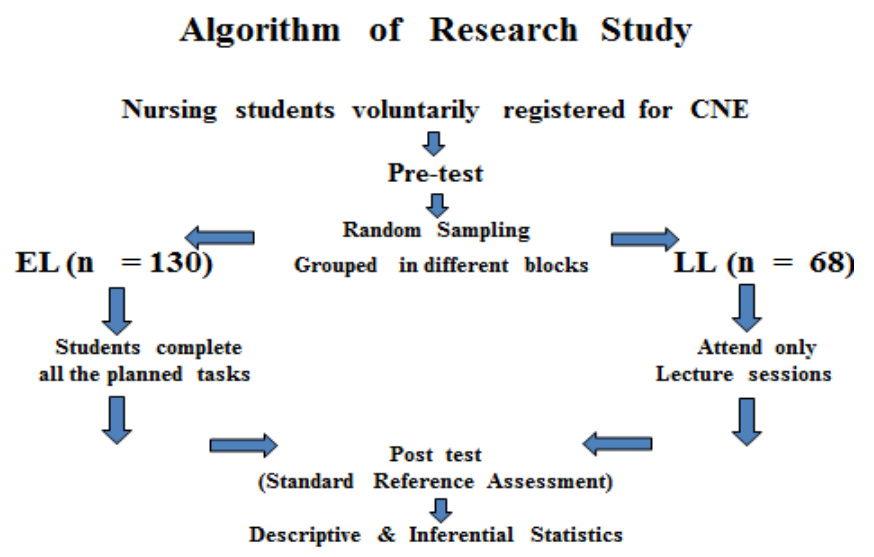

\subsection{Result}

\section{Findings and Discussion}

Overall pre-test knowledge score was $8.2+/-4.56$ and post test score was $11.6+/-3.2$ in control group. Experimental group's pre-test score was $8.5+/-5.4$ and post test score was $15.2+/-3.5$. Group with Lecture Learning $37.9 \%$ had gained knowledge from average to good / excellent level \& in group with Engaged Learning $88 \%$ had similar level of knowledge gain. (with $t=11.08$ and 28.34 respectively at $p<0.05$ significance level)

Fig 1 Sample distribution

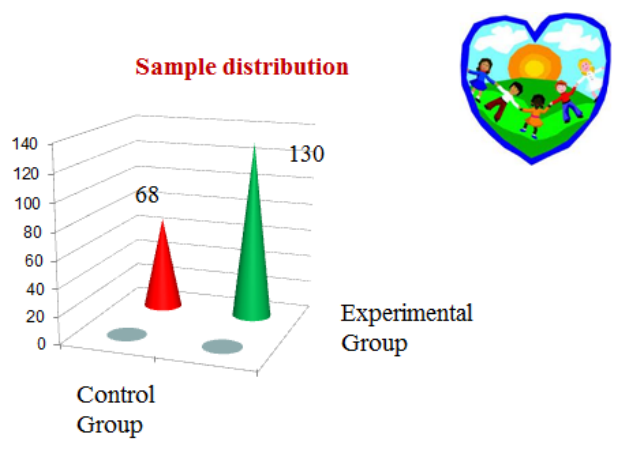

Fig 2 Overall scores of both group

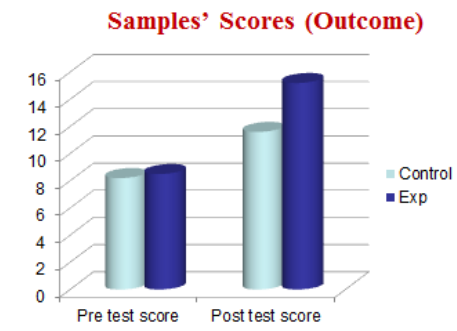

Statistical views:

* Change between Groups

* Change within Groups
Table 1 Scores \& grading of samples

Scores Grading of Samples

\begin{tabular}{lll} 
Grading & Score & Percentage \\
\hline Excellent & $15 / 20 \&$ above & $75 \%$ \& above \\
Good & $12 / 20-14 / 20$ & $60-74 \%$ \\
Average & $<12 / 20$ & $<60 \%$ \\
Fail & $<10 / 20$ & $<50 \%$
\end{tabular}

Table 2 Scores of experimental group Itemised scores-Experimental Group (\% r/off)

\begin{tabular}{|c|c|c|c|c|c|c|}
\hline \multirow{2}{*}{$\begin{array}{r}\text { Scores } \\
\text { Assessment Tasks }\end{array}$} & \multicolumn{2}{|c|}{ Excellent } & \multicolumn{2}{|c|}{ Good } & \multicolumn{2}{|c|}{ Average } \\
\hline & Pre test & $\begin{array}{c}\text { Post } \\
\text { test }\end{array}$ & $\begin{array}{l}\text { Pre } \\
\text { test }\end{array}$ & $\begin{array}{l}\text { Post } \\
\text { test }\end{array}$ & $\begin{array}{l}\text { Pre } \\
\text { test }\end{array}$ & $\begin{array}{l}\text { Post } \\
\text { test }\end{array}$ \\
\hline NALS & 7 & 60 & 10 & 34 & 83 & 6 \\
\hline PALS & 12 & 54 & 14 & 44 & 74 & 2 \\
\hline $\begin{array}{l}\text { IV / Drug } \\
\text { Calculation }\end{array}$ & 6 & 92 & 63 & 5 & 31 & 3 \\
\hline $\begin{array}{l}\text { Umbilical Vein } \\
\text { Catheterisation }\end{array}$ & 3 & 76 & 36 & 19 & 61 & 5 \\
\hline Cord Prolapse & 13 & 96 & 48 & 4 & 39 & 0 \\
\hline PPH Management & 4 & 97 & 56 & 2 & 40 & 1 \\
\hline ACLS & 9 & 97 & 68 & 2 & 23 & 1 \\
\hline Video / Quiz & - & - & - & - & - & - \\
\hline
\end{tabular}

Table 4 Grading shift by experimental group 
Lecture Learning Method (Control Group) $n=68$

Pre test score

\begin{tabular}{|c|c|c|c|c|c|}
\hline \multicolumn{2}{|c|}{ Excellent } & \multicolumn{2}{c|}{ Good } & \multicolumn{2}{c|}{ Average } \\
\hline $\mathbf{n}$ & $\%$ & $\mathbf{n}$ & $\%$ & $\mathbf{n}$ & $\%$ \\
\hline 4 & 5.88 & 19 & 27.9 & 45 & 66.17
\end{tabular}

Post test score

\begin{tabular}{|c|c|c|c|c|c|}
\hline \multicolumn{2}{|c|}{ Excellent } & \multicolumn{2}{c|}{ Good } & \multicolumn{2}{c|}{ Average } \\
\hline $\mathbf{n}$ & $\%$ & $\mathbf{n}$ & $\%$ & $\mathbf{n}$ & $\%$ \\
14 & 20.5 & 22 & 32 & 32 & 47.05 \\
\hline
\end{tabular}

$(\mathrm{d}=4.3$, $\mathrm{sd}=3.2$, paired ' $\mathrm{t}$ ' $=11.08, \mathrm{p}<0.05)$
Engaged Learning Method (Exp. Group) $\mathbf{n}=130$

Post test score

\begin{tabular}{|c|c|c|c|c|c|}
\hline \multicolumn{2}{|c|}{ Excellent } & \multicolumn{2}{c|}{ Good } & \multicolumn{2}{c|}{ Average } \\
\hline $\mathbf{n}$ & $\%$ & $\mathbf{n}$ & $\%$ & $\mathbf{n}$ & $\%$ \\
\hline 7 & 10.2 & 14 & 20.5 & 47 & 69.1 \\
\hline
\end{tabular}

Post test score

\begin{tabular}{|c|c|c|c|c|c|}
\hline \multicolumn{2}{|c|}{ Excellent } & \multicolumn{2}{c|}{ Good } & \multicolumn{2}{c|}{ Average } \\
\hline $\mathbf{n}$ & $\%$ & $\mathbf{n}$ & $\%$ & $\mathbf{n}$ & $\%$ \\
\hline 51 & 75 & 14 & 20.5 & 3 & 4.41 \\
\hline
\end{tabular}

$(d=8.7$, sd $=3.5$, paired ' $t$ ' $=28.34, p<0.05$ )

\subsection{Framework evolution for technology-based teaching and learning}

Greg Kearsley \& Ben Shneiderman meaningfully engaged in learning activities through interaction with others and worthwhile tasks. Fuszard, focused on the students' learning outcomes (i.e. how much and how well the students have learnt).

Burns \& Squires, upheld the manner one can build upon the interests of the students and individualize their classroom experience Integral to this programme is the completion of projects, reports, and group activities to evaluate a student's thoughts and process of development

Knowles fostered engagement and interactivity in the classroom and capitalize on the strengths of instruction responsive to student needs.

Jones, Valdez, Nowakowski, and Rasmussen engaged learning act as a "compass" for reform instruction, helping educators chart an instructional course and maintain an orientation based on a vision of engaged learning and what it looks like in the classroom and community.

Marjorie King, Lois W. Witney quasi-experimental study involved a convenience sample of senior student nurses felt that "they always help and enable us to use our critical thinking skills."

In a scenario with rich text information on Constructivism theory but paucity of evidence research on engaged learning activities in health sciences education, this study epitomize the role of tangent teaching methods in imparting education to undergraduate students in nursing, view shared by Knowles (1970), Marjorie King, Lois W. Witney (2010).

* The unique environment allows for students and participant to develop skills and knowledge of the clinical environment in a way that mirrors that of the clinical setting but is not only better but 'safer than the real thing

* Fosters a culture of discovery and supports exemplary health sciences research

* Hallmark programs can be developed through

* They enjoyed being consulted about the sequencing and scheduling of course content, examinations

* Relate-Create-Donate knowledge

* Finally, the need for research endeavours

\section{Conclusion}

Engaged learning is intended to be a conceptual framework for technology based education that can result expected outcome by nursing students in recognition of the changing needs of the 21 st century. By EL over LL nursing students are likely to be intrinsically motivated to learn due to the meaningful nature of the learning environment and activities. Better than a thousand days of diligent study is one day with a great teacher.

* Dr. Pratibha Chandekar, PIMS. Loni

\section{Acknowledgement}

* Principals, CONs, Pune

* Statisticians \& PSM Dept, AFMC, Pune

* Nursing students who participated in the study

* My mother Mrs. V Seethalakshmi 


\section{References}

[1]. Davis, M. A., \& Henry, M. J. (1997). Cognitive capacity of non-traditional learners in two instructional settings. Research/ Technical Report

[2]. Fuszard, B. (1995). Innovative teaching strategies in nursing (2nd ed.). Gaithersburg, MD: Aspen

[3]. Gross, P. (1997, February). Engaging the disengaged: How is it different when using distance education? Position Paper. Speech/Conference Paper

[4]. Jones, B. F., Valdez, G., Nowakowski, J., \& Rasmussen, C. Plugging in: Choosing and using educational technology. EdTalk. Washington, DC: Council for Educational Development and Research.

[5]. Knowles, M. S. (1970). The modern practice of adult education. New York: Association Press.

[6]. Myer, S., Brenner, Z. R., \& Wood, K. (1995). A comparison of learner outcomes to traditional and videotaped classes. Nurse Educat or, 20(2), 29-33

[7]. Macmanaway L A (1970) Teaching methods in higher education, innovation and research Universities Quarterly. Vol 24. No. 3 p. 321- 329

[8]. Harley J \& Cameron A Some observations on the efficiency of lecturing. (1967) Educational Review 20 p. 30 - 37

[9]. http://www.brookes.ac.uk/services/ocsld/resources/20reasons.html 